\title{
The Principle of Population for the 21st Century: The Never Coming Stationary State ${ }^{1}$
}

\section{Martin Machay ${ }^{2}$}

\begin{abstract}
Forward-thinking is one of the most enchanting areas in economics. While Malthus and Ricardo agreed on the gloomy vision of the future, Mill described the wider stationary state and foresaw it in a more optimistic way. Space sciences and improvements in our technology provided us with the solution decades ago, although economics have not noticed this possible solution of the classical stationary state until now. This article incorporates this knowledge into economics. Calories integrate the supply of means of production and the demand for means of consumption in one market. The stationary state could come only if the demand for means of subsistence grows faster than the supply of means of production. Increasing scarcity of free calories exceeding the minimal required volume of it preventing the malnutrition and death will push the calorie price up while economy will move towards the stationary state. But where to get the land when the very last piece of it - even the deserts - will have been already cultivated? Increasing scarcity of land opens possibility for firms to make profit from producing land. Thus, the classical stationary state is only an illusion.
\end{abstract}

Key words: stationary state, terraforming, food, population growth, nutrition, space economics

JEL Classification: J11, Q11, Q15, Q21, Y90

\section{Introduction}

More than 200 years ago Thomas Malthus gave life to a terrifying vision of future full of hunger, despair and misery. He reacted to the everyday situation of the nineteenth century and created a simple principle that does not want to leave social sciences even after so many years. Though his principle was inappropriately erased from economics by the powerful idea of substitution, it successfully survives or thrives in various areas of environmentalism.

Economics - like any leading science of its era - suffers from strong self-confidence. It stubbornly ignores other sciences and overestimates its own tools like substitution. A magic of substitution may be astonishing but it is petty in cases when there is no substitute at all - like food.

\footnotetext{
${ }^{1}$ Previously published as WP No. 18/2012 at Faculty of Business and Economics of Mendel University in Brno.

${ }^{2}$ Faculty of Economics and Administration - Department of Economics, Lipová 41a, 60200 Brno, Czech Republic
} 
It seems to be useless to bring the classical stationary state back to economics again in times of obesity and European excesses in food production. No matter how trivial it is to reconsider the stationary state now, it is one of the very first economic questions stated that has not been answered yet. Moreover, we enjoy wider imagination in our days that provide us plenty of possibilities how to reverse the sad Malthusian future. Terraformation will be one of them.

The following theoretical text is an attempt to provide a possible solution to the classical stationary state. I admit it might make an impression of a silly solution for economists who forgot to look far into the future. But looking forward shall be an important aspect of economics should dangers the future may place in front of us be avoided - like the classical stationary state.

\section{The starvation future}

What is a stationary state? It is a time of no or very small changes due to some limitation. More precisely, it is limitation of means of subsistence imposed to the growing population. Classical stationary state expresses simple idea. Population cannot grow indefinitely because the Earth cannot provide indefinite means of subsistence for an infinite population.

\subsection{Malthus}

The future of malnutrition was outlined by Thomas Malthus in his famous "An Essay on the Principle of Population" (Malthus, 1807). He was also the first economist to even bring the forward thinking to economic science.

His stationary state described in his book evolves from two postulates. First, "That food is necessary to the existence of man". Second, "That the passion between the sexes is necessary and will remain nearly in its present state." (Malthus, 1807)

While we cannot doubt that the first is true, the second one is questionable. "Passion between the sexes" did not change obviously but it is not what Malthus meant. He spoke about bringing descendants. This is what is doubtful because this has substantially changed in developed countries in those two hundred years.

Even though the birth rate has dropped in developed countries, the world population growth remains relatively high and the world population grows by 1.2 percent per annum (UN, 2008). The number seems to be low but the long-term implications are significant. If the same process repeats in developing countries, there will be only 9 billion people in the world by 2300 . However, if the birth rate stays high, as UN predicts in one scenario, there will be up to 36.4 billion people by 2300 (UN, 2004). A population of this size must be fed. It is possible that the classical stationary state will become a major aspect of mainstream economics again.

Malthus, nevertheless, did a crucial mistake - his demand and supply do not match each other - they do not have a common denominator. While demand was represented by the amount of people and misty "means of subsistence". Land and "means of production" were behind the supply. Hence, he describes the situation in the market that does not exist. Moreover, he starts his theory right from the stationary state. His initial situation 
is already a stationary state. More precisely a situation when means of subsistence and of production are equalized.

He applies the two ratios of growth of the population and of subsistence to the stationary state. Quoting Malthus "Population, when unchecked, increases in a geometrical ratio. Subsistence increases only in an arithmetical ratio" (Malthus, 1807). It is easy then to plot the future full of misery using these two ratios. He also found the support for his conclusions in everyday reality of his era. Moreover, he completely neglected the technological growth.

But Malthus' principles did not disappear even after two hundred years. His idea of linear forecast of contemporary trends is still too alive. How many times did we hear apocalyptic visions of resource depletion - usually originating outside economics? The reason of this attractiveness is its simplicity. Take today's trend and prolong it to the future. This approach always ends with depletion of resources.

\subsection{Ricardo}

The Malthusian future was so tempting that even David Ricardo could not miss it in its book "On the Principles of Political Economy and Taxation" (Ricardo, 1821). Nevertheless, his area of interest was the supply - more precisely the "produce of the earth". The tool he used was rent.

It is rent that has the power to pull land to the economic life of the society. Hence, to use "original and indestructible powers of the soil", or food, in today's language.

He presented an astonishing analysis that shadowed the Malthusian one. Ricardo starts at the beginning and not from the stationary state like Malthus. His detailed explanation illustrates how increasing rent due to increasing demand of means of subsistence involves land, which had not been used in agriculture before, to the agricultural activities. However, less "fruits of nature" arise with decreasing fertility of such land.

Because land is "limited in quantity", the fruits it gives must be limited, too. After accepting Malthusian principle of population growth, the only logical conclusion for Ricardo is that the economy moves towards the stationary state! Moreover, he fully recognized the changing technological level he calls "improvements in agriculture". These improvements "are of two kinds: those which increase the productive powers of the land, and those which enable us, by improving our machinery, to obtain its produce with less labour" (Ricardo, 1821). They could be called the technological growth and increasing role of the capital nowadays. Unfortunately, it plays minor role in his ideas, so it cannot reverse the sad future.

He interpreted the stationary state in a gutsier way then Malthus - "the only remedies are either a reduction of people, or a more rapid accumulation of capital" (Ricardo, 1821). However, "the latter is neither very practicable nor very desirable" (Ricardo, 1821).

Ricardo's way to the stationary state is more sophisticated then Malthus' but the conclusion is the same - hunger, misery and poverty. 


\subsection{Mill}

Mill, with no doubts, accepted the very inevitability of the stationary state in his "Principles of Political Economy with some of their Applications to Social Philosophy" (Mill, 1866). Quoting Mill "It must always be seen, more or less distinctly, by political economists, that the increase of wealth is not boundless: that at the end of what they term the progressive state lies the stationary state" (Mill, 1866). His thoughts focused on the stationary state itself rather than on the principles of the way towards it.

However, he abandoned the interpretation based on misery and whished - more than constituted - the interpretation as mental rather than economic growth of humanity. $\mathrm{He}$ also adds "It may be a necessary stage in the progress of civilization" (Mill, 1866). He determined the then situation of developed countries to be stationary. These countries in his opinion - are already in the stationary state! However, they will not be in the stationary state even after very, very long time from now. But his opinion expresses quite well the mood and self-confidence elites had in the nineteenth century.

What has been mentioned above brings up a question - why to even mention Mill in the stationary state context? Because his stationary state does not arise from the limited means of production of food or limited land only, but from "all" causes of "zero" growth. The Mill's stationary state becomes expected and foreseeable after economics finally realizes that no growth is unlimited (like economists with at least little technical background already do or should). If one understands the crucial differences in various stationary states then he or she must agree with Mill's interpretation of it like the time of only mental progress and not economic growth.

Thus, Mill ends - very positively - the discussion about the stationary state.

\subsection{Modern economics killed the stationary state}

The classical stationary state disappeared from the mainstream economics due to two fatal aspects. The first one was the real development of economy when technological growth in agriculture outstripped the growth of the population so much that in the developed world, the most dangerous murderer of our times is obesity. The second one was and still is the powerful idea of substitution.

It is impossible not to notice that the Malthusian principle of simple linear forecasts is very popular especially in other sciences. Economics does not perceive the Malthusian principle as a problem because it already has the answer for non-renewable resources. Resource economics has developed into perfection the Hotelling's model (Hotteling, 1931). The perfection is based on two very important aspects: backstop resources simply said it is another or artificial resource used as a replacement to original resource; or completely different technology that may be used as a replacement to the one used before. Both of them can be defined as substitution - simple replacement of one process used in a production for another.

Price of a specific resource - or more precisely its relative height to the price of a possible substitute is the tool causing these changes. This principle applies to backstop resources and to diverse technology of production (see for example Oren and Powel, 1985). 
The contemporary economics considers the Malthusian problem to be solved. But economics solved only the goods production part. The classical stationary state has not been solved because contemporary economics believes in the powers of substitution as blindly as classical political economy did the cheerless situation behind their windows. Stanley Jevons has expressed this misleading idea very clearly: "The same, or nearly the same, substance is often obtained from two or three sources. The constituents of wheat, barley, oats, and rye are closely similar, if not identical. Vegetable structures are composed mainly of the same chemical compound in nearly all cases. Animal meat, again, is of nearly the same composition from whatever animal derived. There are endless differences of flavour and quality, but these are often insufficient to prevent one kind from serving in place of another." (Jevons, 1879).

Why did not we notice that food itself does not have any substitute? How can we replace food? Can we simply produce it in our factories from chemicals or raw materials? Can we artificially make food for billions of people? We will always need land and agriculture to provide the means of subsistence.

There is also a reversed interpretation of the stationary state in modern economics. Not land - more precisely its fruits - is the limit to the population but people are the limit to products of soil. This reversed point of view is presented by for example Johnson (2000). It was the farmers who have changed processes of food production to achieve larger surpluses of it over farmers' own food consumption as a consequence of population growth.

However, such an interpretation of the stationary state is nothing else but technological growth in agriculture outstripping the growth of the population. Moreover, this interpretation lacks the wide view the classics had. Land is a limited resource. Its limitation naturally passes on the fruits of it. Hence, we are back at the classical stationary state - if there is a limit to agricultural production, the population cannot grow indefinitely.

The problem stated by Malthus and Ricardo remains in existence. It receded due to technological growth in agriculture but the extent of land did not change. On the contrary - it lessens as the result of its incorrect use or chemical pollution. The growing world population indicates that the stationary state of hunger and misery may come one day. And economics? Remains silent.

\section{New theory of population growth}

Having examined the historic evolution of the stationary state, I shall present to the reader my own interpretation of the stationary state and original conclusions which arise from this brand new theory that is published for the very first time. The model presented in chapter 3 and 4 provides a very basic economical model for a prospective following analysis.

To reconsider the stationary state, one must avoid the crucial mistake the classics did non-uniform demand and supply. It is true that people determine demand for food and that land determines supply of it. But calories are the common denominator.

Calories that we are able to produce at our technological level from disposable land that is used in agriculture represent a supply of means of subsistence. Demand shall be 
represented by the calories that people want or need to eat in order to satisfy their utility, or to simply survive in the case they are in the stationary state already.

The minimal amount of calories one average person must consume per unit of time $\mathrm{e}^{3}$ will be referred to as consumption needed $-c_{N}$. The minimal amount of calories the population must consume in time $t$ not to suffer from or die of malnutrition can be easily expressed as

$$
L(t) c_{N}
$$

where $L(t)$ is the total population in time $t$.

The area of land that is - for now - not cultivated by agricultural technology - hence, fully in the power of nature itself - can still provide calories entirely just by nature. As it has been already said, land is a limited resource on Earth. Thus, the calories provided just by nature (i.e. without any human activity) freely on all disposable land can be referred to as $-a_{T}$. Calories extracted from $a_{T}$ can vary in time due to technological improvements in agriculture. The total calories provided by all disposable land in time $t$ can be expressed as

$A(t) a_{T}$,

where $A(t)$ is technological level in time $t$.

Assumption 1: Let us suppose that food, or calories, to be more precise, is distributed among the world population equally.

The consumption surplus $\left(c_{S}\right)$ - or how many people can be fed from current calories share of one person - is expressed by a fraction of (1) and (2):

$c_{S}=\frac{A(t) a_{T}}{L(t) c_{N}}$.

Assumption 2: Let us assume the population and technological level to grow at constant rates $n>0$ and $g>0$.

Discounting (3) to the "beginning" of time and equalling $L(0)$ and $A(0)$ to one yields

$c_{S}=\frac{e^{g t} a_{T}}{e^{n t} c_{N}}=e^{(g-n) t} \frac{a_{T}}{c_{N}}$.

The expression in (4) represents the size of consumption surplus at any time $t$.

\footnotetext{
${ }^{3}$ It is not the aim of this article to investigate the medical aspects of this but - just to make a picture - an average person needs approximately 1,200 calories per day to survive, which is 438,000 calories per year (Sarah, 2011).
} 


\subsection{Stationary state}

If classical political economy describes the stationary state as a moment in time when population growth is not possible any longer, then it means the situation of calories production and calories consumption is equalized. In another words, $c_{S}=1$. Moreover, there cannot be any higher demand for calories than is the supply of them. This implies that $c_{S} \in(\infty, 1]$. Substituting one for $c_{S}$ in (4) yields

$$
\begin{aligned}
& 1=e^{(g-n) t} \frac{a_{T}}{c_{N}} \\
& \frac{c_{N}}{a_{T}}=e^{(g-n) t} \\
& \log c_{N}-\log a_{T}=(g-n) t \\
& t_{P}=\frac{\log c_{N}-\log a_{T}}{g-n},
\end{aligned}
$$

where $t_{p}$ is the time when the means of subsistence are equal to the means of production. Moreover, $t_{p}>0$ must be accomplished for the classical stationary state to come. Because $\log c_{N}-\log a_{T}$ is logically smaller than zero, then also $g-n$ must be negative. This implies that $g<n$ must be true for the stationary state to come.

Theorem 1: Population growth rate must be higher than the rate of technological growth should the stationary state become real in the future. In another words, if technological growth exceeds the population growth, there will never be the stationary state in the future.

Notice that it does not imply that this could not happen in the real world for a "short" period of time - two hundred years, for example. The alternation of times when $g<n$, and when it is contrariwise explains why the stationary state had been noticed in the nineteenth century and why it was forgotten in the last century. 


\subsection{The calorie price}

It is a general custom to model the price time trajectory as $p(t)=p(0) e^{b t}$, where $p(0)$ is usually said to be one and $b$ is a positive constant. Doing this in the case of a calorie market would not reflect surpluses of calories in the concrete time. Thus, the calorie market and the calorie price would not be interconnected. Moreover, this price grows constantly in time, which contradicts the real price evolution in time (empirical evidence for real corn or wheat prices for example in Johnson, 2002).

The calorie price shall be constructed to fulfil the following conditions. First, it shall be stable - it means marginal fluctuations - in times of high food surpluses. Second, it shall rise in times of poor harvests and reversely. Third, it shall continually rise when the economy moves towards the stationary state $\left(\frac{\partial c_{S}}{\partial t}<0 \Rightarrow \frac{\partial p(t)}{\partial t}>0\right)$. Fourth, $\lim _{t \rightarrow t_{P}} p(t)=\infty .^{4}$

These conditions correspond to the price constructed as

$$
p(t)=\frac{\gamma}{e^{g t} a_{T}-e^{n t} c_{N}},
$$

where $\gamma$ is the price for the very last free calorie exceeding the minimal calorie level for the whole population to prevent the malnutrition. ${ }^{5}$

The fluctuations of price per calorie in time of high consumption surpluses are caused by fluctuations in $a_{T}$ due to natural disasters. Hence, land provides less calories extracted from it, causing lower consumption surplus and growing food price. This contraction can also be viewed in a way that land with destructed harvest by natural disaster, or land with poor harvest yields is excluded from disposable agricultural land for one period. This has the same consequences for the calorie price.

Figure 1 represents the graphical formulation of the new classical stationary state.

\footnotetext{
${ }^{4}$ This expresses a simple idea. Imagine a situation when all food is distributed in the population no matter how - in a way that everybody gets only $c_{N}$. What should be the price of one calorie? The fourth condition states that infinity just because one calorie taken and given to somebody else means death to the person who is selling it. It is actually the price one is willing to accept for his or her own death - abstracting from voluntary suicide.

${ }^{5}$ Proof: The very last available calorie exceeding the minimal requirements to shield the whole population from malnutrition can be expressed as $e^{g t} a_{T}-e^{n t} c_{N}=1$. Hence, $p(t)=\frac{\gamma}{1}=\gamma$.
} 
Figure 1: The different growth rates of means of production and of consumption, the calorie price and the consumption surplus.

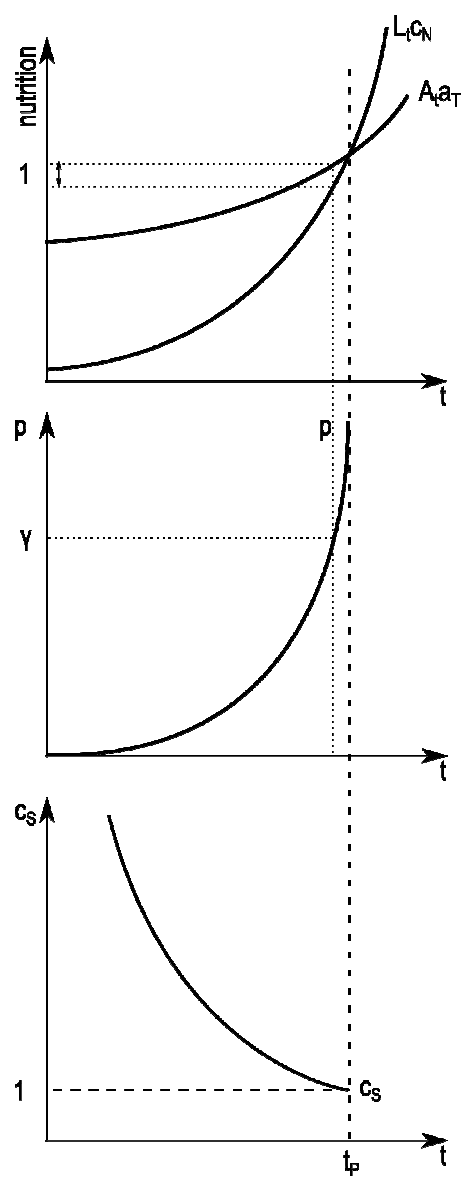

Source: Illustration by the author.

Though the classics could not mathematically express their ideas and though their demand and supply of means of subsistence and means of production did not match each other, their idea of the stationary state - in the context of the nineteenth century was correct after all.

The huge difference that separates us from the classics is imagination. While - as it was a custom for several centuries - the society had an opinion of its technological level being at a peak, the truth is we do not know which inconceivable technologies are hidden behind a persistent work of generations to come. We grasp ideas of the classics but we can do much more than that - we can finally enrich their ideas with a possible solution to eliminate the gloomy vision of hunger and misery from economics once and for all. 


\section{The land production}

Imagination and findings of natural sciences have been noticeably different since the times of Malthus, Ricardo or Mill. Our technology provides us with more opportunities than any of the classics could have ever foreseen.

Combining the two we realize that - in the context of agricultural land - we may not be limited to land located on the planet Earth only. Economics as the leading social science should incorporate the newest level of knowledge of other sciences, too. Hence, it is necessary to upgrade the classical stationary state.

Process that enable us to produce habitable - thus agriculturally exploitable - planets is called terraformation. It is an aimed and by man caused activity altering conditions of a celestial body to support Earth-type life without using another technological support. While technological and practical dimensions of terraformation are satisfactorily elaborated (see for example Averner and MacElroy, 1979, or Badescu, 2004) and terraformation is perceived as inevitable by natural sciences (Maccone, 2008), economics remain silent. The following text introduces a brand new dimension to economics and returns the long forward view the classics once had.

\subsection{Terraforming firm}

Let us assume a firm whose activities focus on a habitable planets production. Its revenue results from selling area of land on a new habitable planet.

Assumption 3: Assume that revenues of the company are made by selling land, and are calculated as a multiple of calories provided by nature on that land and the calorie price.

Thus

$$
R=a_{L} p=a_{L} \frac{\gamma}{e^{g t}\left(a_{T}+a_{L}\right)-e^{n t} c_{N}},
$$

where $a_{L}{ }^{6}$ is the total area of land on the newly produced planet, for example "Lantor" designated as $L$. Notice the firm will sell the land after the terraformation for the calorie price that does not correspond to $a_{T}$ but $a_{T}+a_{L}$. Newly produced agricultural land decreases the calorie price as a consequence of higher means of production - hence, the higher consumption surplus. The proof is very simple.

\footnotetext{
${ }^{6}$ Notice that we speak in the text about an area of land but we mean an amount of calories arising from this area of land naturally just by the productive forces of nature without any intervention of man. It is because it fully depends on the amount of land only.

${ }^{7}$ Proof: the profit of the firm in time $t$ is as usually $\pi(t)=R(t)-C(t)$. If a purely competitive firm decided to terraform in a situation of $\pi(t)=0$ and if its expected revenue is based on $E(R(t))=a_{L} \frac{\gamma}{e^{g t} a_{T}-e^{n t} c_{N}}$, it yields $C(t)=E(R(t))$. However, its real revenue will be based on the calorie price after the terraformation. Combining this yields
} 
To understand the costs of terraformation, one needs to understand the very process of it. The biggest problem of most of celestial bodies is lack of water. There is plenty of water in space but its concentration is low, and it is usually spread over wide areas. Water must be delivered to the celestial bodies that will succumb to terraformation "soon". The rest of the process comprises of "routine" at-the-place activities such as atmosphere adjustments.

Thus, costs can be divided into autonomous component that consists of costs of technical equipment, raw materials and chemicals and productive forces and of variable costs that are used to deliver water in the form of - for example asteroids - to the location of designation. Hence

$C(t)=C_{A}(t)+c(t) q_{w}$,

where $C_{A}(t)$ are autonomous costs in time $t, q_{w}$ is the quantity of water that must be delivered to the celestial body in order to support functional Earth-type ecosystem, and $c(t)$ are costs of delivering one unit of water. ${ }^{8}$ Moreover, the $q_{w}$ is exogenous. ${ }^{9}$

However, terraformation technologies and their costs can be changed due to the technological growth.

Assumption 4: Let us suppose that there is only one technological growth rate $(g)$ in the economy that is applied to the agriculture as well as to terraformation technologies.

Hence, we can rewrite the (8) as

$C(t)=C_{A}(1) e^{-g\left(t-t_{1}\right)}+c(1) e^{-g\left(t-t_{1}\right)} q_{w}$,

where $C_{A}(1)$ are autonomous costs at the time when terraformation is technologically possible for the first time $\left(t_{1}\right), c(1)$ are costs of delivering one unit of water at the time $t_{1}$. Technological development decreases costs of terraformation by a rate $g$ per unit of time. Rearranging (9) yields

$\pi(t)=a_{L} \frac{\gamma}{e^{g t}\left(a_{T}+a_{L}\right)-e^{n t} c_{N}}-a_{L} \frac{\gamma}{e^{g t} a_{T}-e^{n t} c_{N}}$
$\pi(t)=a_{L} \gamma\left(\frac{1}{e^{g t}\left(a_{T}+a_{L}\right)-e^{n t} c_{N}}-\frac{1}{e^{g t} a_{T}-e^{n t} c_{N}}\right)$. Hence, $\pi(t)<0$. The firm with such expectations ends up in loss.

${ }^{8}$ Notice they are constant at the time $t$. There is the closest single spot where water is taken from - just for simplicity.

${ }^{9}$ There is some water at the celestial body already (designated as $q_{w 0}$ ). And there is a minimal amount of water necessary to support Earth-type ecosystem $\left(q_{\min }\right)$. Hence, $q_{w}=q_{\min }-q_{w 0}$. The firm is not interested in higher amount of water because it would increase the costs of terraformation, and also reduce the $a_{L}$ as a consequence of increasing level of water at the celestial body. 
$C(t)=e^{-g t}\left(C_{A}(1) e^{g t_{1}}+c(1) e^{g t_{1}} q_{w}\right)=e^{-g t} C_{0 L}$,

where $C_{0 L}$ are the terraformation costs discounted to the "beginning of time". These costs decrease in time due to technological development.

Suppose pure competitive firm that will terraform as soon as $\pi(t)=0$. This naturally implies that $R(t)=C(t)$. Hence, if (7) and (10) are equal, we can compute the time when terraformation will run purely on the competitive market basis $\left(t_{T}\right)$.

$a_{L} \frac{\gamma}{e^{g t} a_{T}+e^{g t} a_{L}-e^{n t} c_{N}}=e^{-g t} C_{0 L}$

$a_{L} \gamma=C_{0 L} a_{T}+C_{0 L} a_{L}-e^{(n-g) t} c_{N} C_{0 L}$

$\frac{a_{L} \gamma}{C_{0 L}}-a_{T}-a_{L}=-e^{(n-g) t} c_{N}$

$e^{(n-g) t} c_{N}=a_{T}+a_{L}-\frac{a_{L} \gamma}{C_{0 L}}$

$(n-g) t+\log c_{N}=\log \left(a_{T}+a_{L}-\frac{a_{L} \gamma}{C_{0 L}}\right)$

$t_{T}=\frac{\log \left(a_{T}+a_{L}-\frac{a_{L} \gamma}{C_{0 L}}\right)-\log c_{N}}{n-g}$.

We have all the tools we needed to solve the mystery of the stationary state. If terraformation takes place earlier than the stationary state becomes a reality, we can finally prove the future of misery and hunger false. Formally stated $t_{T}<t_{P}$ must be fulfilled.

$t_{T}-t_{P}<0$

$\frac{\log \left(a_{T}+a_{L}-\frac{a_{L} \gamma}{C_{0 L}}\right)-\log c_{N}}{n-g}-\frac{\log c_{N}-\log a_{T}}{g-n}<0$

$\frac{\log \left(a_{T}+a_{L}-\frac{a_{L} \gamma}{C_{0 L}}\right)-\log a_{T}}{n-g}<0$

Because $n-g>0$ (Theorem 1), then 
$\log \left(a_{T}+a_{L}-\frac{a_{L} \gamma}{C_{0 L}}\right)<\log a_{T}$

$a_{T}+a_{L}-\frac{a_{L} \gamma}{C_{0 L}}<a_{T}$

$a_{L}<\frac{a_{L} \gamma}{C_{0 L}}$

$C_{0 L}<\gamma$.

If (13) holds true, then terraformation will take place earlier than the classical stationary state will come about. In other words, the stationary state will never occur. Terraformation will therefore overtake the stationary state just by the time equal to (12).

The Figure 2 illustrates how terraformation activities of firms will repeatedly avert the stationary state.

Figure 2.: The consequences of the terraformation process

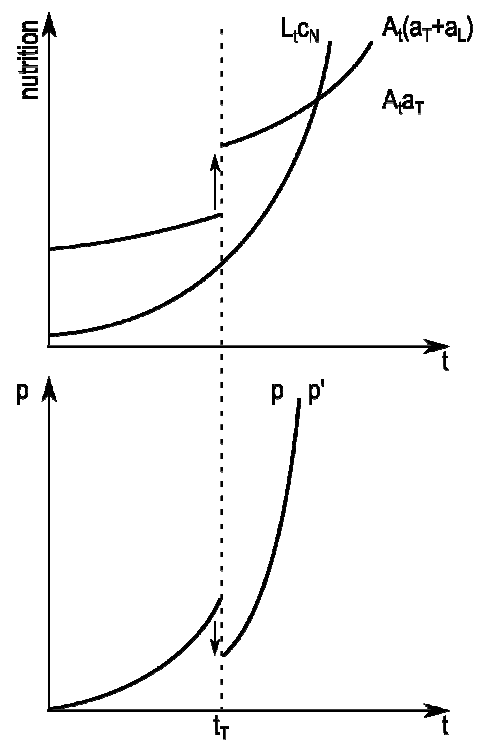

Source: Illustration by the author.

Free market can push the gloomy future of misery to the further future indefinitely. But classics could not have known that. It was just impossible for them to look forward and see this possibility. Nevertheless, economics has finally answered one of the most thrilling questions it stated in its long science history. 


\subsection{Firm's celestial bodies preferences}

Space is full of celestial bodies that can be suitable for terraformation. How will a firm choose the celestial bodies for terraformation?

Suppose that a firm will be deciding between two celestial bodies (let us designate them as $L$ and $M$ ). Both of them will be endowed with the same amount of agricultural land after terraformation $\left(a_{L}=a_{M}\right)$. However, the costs of terraformation discounted to the "beginning of time" will be different. Thus, $C_{0 M}=\alpha C_{0 L}$ for $\alpha \neq 1$ and $\alpha>0$. Let us further suppose that the firm will choose the celestial body $L$ for terraformation. Hence, terraformation of $L$ will take place earlier than the one of $M$. Formally expressed $t_{L}-t_{M}<0$. Which $\alpha$ does this hold for?

$$
\frac{\log \left(a_{T}+a_{L}-\frac{a_{L} \gamma}{C_{0 L}}\right)-\log \left(a_{T}+a_{M}-\frac{a_{M} \gamma}{C_{0 M}}\right)}{n-g}<0 .
$$

From Theorem 1 we already know that $n-g>0$. Hence,

$$
\begin{aligned}
& \log \left(a_{T}+a_{L}-\frac{a_{L} \gamma}{C_{0 L}}\right)-\log \left(a_{T}+a_{L}-\frac{a_{L} \gamma}{\alpha C_{0 L}}\right)<0 \\
& a_{T}+a_{L}-\frac{a_{L} \gamma}{C_{0 L}}<a_{T}+a_{L}-\frac{a_{L} \gamma}{\alpha C_{0 L}} \\
& \alpha>1
\end{aligned}
$$

This implies that $C_{0 L}<C_{0 M}$.

Theorem 2: If there are two celestial bodies with the same amount of agricultural land after the possible terraformation but with different terraformation costs discounted to the "beginning of time", firm chooses the celestial body that is cheaper to terraform.

This result is intuitive. Any economist would actually anticipate such a result.

Let us suppose that a firm can decide between another two celestial bodies - designated again as $L$ and $M$. Terraformation costs discounted to the "beginning of time" will be the same in this case $\left(C_{0 L}=C_{0 M}\right)$. The amounts of agricultural land after the terraformation will differ in a way that $a_{M}=\beta a_{L}$ for $\beta \neq 1$ and $\beta>0$. Let us suppose that the firm will choose $L$ to terraform earlier than $M$. Formally $t_{L}-t_{M}<0$. Which $\beta$ does this hold for?

$$
\frac{\log \left(a_{T}+a_{L}-\frac{a_{L} \gamma}{C_{0 L}}\right)-\log \left(a_{T}+a_{M}-\frac{a_{M} \gamma}{C_{0 M}}\right)}{n-g}<0
$$




$$
\frac{\log \left(a_{T}+a_{L}\left(1-\frac{\gamma}{C_{0 L}}\right)\right)-\log \left(a_{T}+\beta a_{L}\left(1-\frac{\gamma}{C_{0 L}}\right)\right)}{n-g}<0
$$

The theorem 1 implies $n-g>0$.

$$
\begin{aligned}
& \log \left(a_{T}+a_{L}\left(1-\frac{\gamma}{C_{0 L}}\right)\right)<\log \left(a_{T}+\beta a_{L}\left(1-\frac{\gamma}{C_{0 L}}\right)\right) \\
& 1<\beta
\end{aligned}
$$

(15) implies $a_{L}<a_{M}$.

Theorem 3: If there are two celestial bodies with the same terraformation costs discounted to the "beginning of time" but with different amounts of agricultural land after possible terraformation, the firm chooses to terraform that celestial body which will provide smaller amount of agricultural land.

Theorem 3 may seem to be contra-intuitive but the price fall - constructed in (6) and more precisely in (7) - will not provide sufficient revenues to prevent the firm from ending in loss even though the celestial body $M$ will supply the market with a larger amount of agricultural land - hence calories.

In other words, it means that there is always a drop in price after terraformation. This drop is the greater the larger is the amount of newly produced land. The fall of the price will cause a fall of revenues in spite of the fact that the firm will sell more land. Therefore, the firm could not cover the terraformation costs in time $t$.

\section{Conclusions}

Forward thinking is one of the most enchanting areas in economics. Every economist does it from time to time, but very rarely with the same conclusions. While Malthus and Ricardo agreed on the doomsday vision of the future, Mill described a wider stationary state and foresaw it in a more optimistic way - the time for mental advancement of all humankind.

Will this dark future ever come? No, it will not. Space sciences and improvements in technology provided us with the solution decades ago, although until now, economics has not noticed this possible solution of the classical stationary.

If an economist limits his or her mind only to what nature has created for us, it is understandable that they see the limit imposed on the population size. But we live in the twenty-first century and it is the right time to improve economics to fit in the new era.

First, we have to unify the supply of means of production and the demand for means of consumption. Calories can integrate both of them in one market. Second, we must allow the technological improvement do its job over the time. The stationary state will come only if the demand for means of subsistence grows faster than the supply of means of production. 
Increasing scarcity of free calories exceeding the minimal required volume of it preventing the malnutrition and death will push the calorie price up, while economy will move towards the stationary state full of misery. Growing calorie price will increase the rent of land which will draw another land with smaller and smaller fertility into the economic life of the society - as Ricardo pointed out so long ago. But where to take the land when the very last piece of it - even the deserts - will have been already cultivated? We will have to produce it.

Third, we must find an economic description of how competitive market will solve the situation by the terraformation. Where the scarcity shows up, the possible profits and opportunities are created. This attracts attention of private firms. Hence, the classical stationary state is only an illusion - always there when we look forward but always moving even further. In truth, it is the never-coming of the stationary state!

\section{Summary}

While Malthus and Ricardo agreed on the doomsday vision of the future, Mill described the wider stationary state. The problem stated by Malthus and Ricardo remains. It receded due to technological growth in agriculture but the extent of land has not changed. To reconsider the stationary state, one must avoid the crucial mistake the classics made - non-uniform demand and supply. Calories can integrate both of them in one market.

We suppose that calories are equally distributed among the world population and assume that population and technological level grow at constant rates. The population growth rate must be higher than the rate of technological growth for the stationary state to become real in the future. The calorie price shall be constructed to fulfil few conditions. First, it shall be stable in times of high calorie surpluses. Second, it shall rise in times of poor harvests, and vice versa. Third, it shall continually rise when the economy moves towards the stationary state.

New - terraformational - technologies help us eliminate the gloomy vision from economics once and forever. Assuming a firm that produces agricultural land on celestial bodies and sells it later, growing calorie price opens a possibility for this firm to be profitable, thus moving the stationary state forward to the future. Theoretical conclusions are intuitive. The firm chooses "cheaper" celestial bodies. It also chooses "smaller" ones due to drops of calorie price after selling the newly produced land. 


\section{References}

AVERNER, M. M., MANELROY, R. D. (1976). On the Habitability of Mars: An Approach to Planetary Ecosynthesis. Ames Research Center, Washington, D.C. Retrieved Septerber $\quad 05, \quad 2011$ from http://ntrs.nasa.gov/archive/nasa/casi.ntrs.nasa.gov/19770005775_1977005775.pdf.

BADESCU, V. (2004). Regional and seasonal limitations for Mars intrinsic ecopoiesis. Acta Astronautica, 56, 7: 670-680.

HOTELling, H. (1931). The Economics of Exhaustible Resources. Journal of Political Economy, 39, 2: 137-175.

JEVONS, W. S. (1879). Theory of Political Economy. London: Macmillan.

JOHNSON, D. G., (2000). Population, Food, and Knowledge. The American Economic Review, 90, 1: 1-14.

JOHNSON, D. G. (2002). The Declining Importance of Natural Resources: Lessons from Agricultural Land. Resource and Energy Economics, 24, 1-2: 157-171.

MACCONE, C. (2008). Protected antipode circle on the Farside of the Moon. Acta Astronautica, 63, 1-4: 110-118. DOI: 10.1016/j.actaastro.2007.12.022

MALTHUS, T. (1807). An Essay on the Principle of Population. London: J. Johnson.

MILL, J. S. (1866). Principles of Political Economy with some of their Applications to Social Philosophy. New York: D. Appleton and Company, New York.

OREN, S. S., POWELL, S. G. (1985). Optimal Supply of a Depletable Resource with a Backstop Technology: Heal's Theorem Revisited. Operations Research, 33, 2: 277-292.

RICARDO, D. (1821). On the Principles of Political Economy and Taxation. London: J. Murray.

SARAH, P. (2011). Approximately How Many Calories Do You Need to Survive? LiveStrong.com, 2011. Retrieved September, 05, 2011 from http://www.livestrong.com/article/300423-approximately-how-many-calories-do-youneed-to-survive/.

UNITED NATIONS (UN), (2004). World Population to 2300. Department of Economic and Social Affairs. Retrieved December 05, 2011 from http://www.un.org/esa/population/publications/longrange2/WorldPop2300 final.pdf.

UNITED NATIONS (UN), (2008). Demographic Yearbook 2008. United Nations Statistics Division, New York. Retrieved December 05, 2011 from http://unstats.un.org/unsd/demographic/products/dyb/dyb2008/Table01 .pdf. 